\title{
The epidemiological profile of the Vascular Birthmark Clinic at the Alberta Children's Hospital
}

\author{
Frankie OG Fraulin MD FRCSC, Ryan K Flannigan BSc MD, Vishal K Sharma BSc MD, \\ Donald F McPhalen MD FRCSC, Robertson A Harrop MD MSc FRCSC
}

FOG Fraulin, RK Flannigan, VK Sharma, DF McPhalen, RA Harrop. The epidemiological profile of the Vascular Birthmark Clinic at the Alberta Children's Hospital. Can J Plast Surg 2012;20(2):67-70.

BACKGROUND: The Vascular Birthmark (VBM) Clinic at the Alberta Children's Hospital (Calgary, Alberta) is a multidisciplinary clinic dedicated to the evaluation of children with vascular anomalies.

OBJECTIVE: To review the characteristics of patients seen at the VBM Clinic.

METHOD: A retrospective data analysis of all pediatric patients presenting to the VBM Clinic between 1998 and 2009 was performed. Data including demographic, referring, diagnostic and treatment information were obtained from the clinic's database.

RESULTS: Of 932 patients, 621 with hemangiomas and 311 patients with vascular malformations were found in the database. Hemangiomas were more commonly found in girls $(68.5 \%)$, and most commonly located on the head and neck (54\%), with most patients $(72.6 \%)$ having only one lesion. Of the patients with hemangiomas, $14.7 \%$ underwent diagnostic imaging investigation and $23.7 \%$ received treatment including medications, surgery, pulsed-dye laser or dressings. The sex distribution among the 311 patients with vascular malformations was almost equal. Venous malformations accounted for $38.9 \%$ of patients, isolated capillary malformations for $31.5 \%$, lymphatic malformations for $11.6 \%$, mixed low-flow malformations for $14.8 \%$ and arteriovenous malformations for $2.9 \%$. Overall, $37.9 \%$ of patients underwent diagnostic imaging investigation and $42.4 \%$ received treatment - either pulsed-dye laser, surgical excision, sclerotherapy or other treatment.

CONCLUSIONS: Hemangiomas and vascular malformations can occur at any anatomical site. There is a large variation in clinical presentation necessitating expertise in a variety of diagnostic approaches and treatment modalities. Vascular anomalies are best managed in a multidisciplinary setting.

Key Words: Birthmark; Clinic; Database; Epidemiology; Hemangioma; Vascular anomaly; Vascular malformation

$\mathrm{T}$ he term vascular anomaly includes two main groups of disorders as classified by Mulliken and Glowacki (1) in 1982: vascular tumours, of which hemangiomas are the most common; and vascular malformations, which can be divided into low-flow and high-flow lesions. The study and treatment of vascular anomalies is progressing with the development of multidisciplinary clinics in many major cities. The Vascular Birthmark (VBM) Clinic at Alberta Children's Hospital (ACH, Calgary, Alberta) evaluates patients from southern Alberta and the adjacent provinces, and makes use of this biological classification for both diagnostic and treatment purposes. Since the establishment of the VBM Clinic in 1997 (2), patients have gone from being treated by individual specialists to a more comprehensive care model of plastic surgeons and pediatricians with a special interest in the care of patients with vascular anomalies. The clinic has grown steadily and now consists of four plastic surgeons, four pediatricians, an interventional radiologist, two dedicated nurses, a dedicated clerk and

\section{Le profil épidémiologique de la clinique des} angiomes de l'Alberta Children's Hospital

HISTORIQUE : La clinique des angiomes de l'Alberta Children's Hospital de Calgary, en Alberta, est une clinique multidisciplinaire vouée à l'évaluation des enfants ayant des anomalies vasculaires.

OBJECTIF : Analyser les caractéristiques des patients vus à la clinique des angiomes.

MÉTHODOLOGIE : Les auteurs ont procédé à une analyse rétrospective des données de tous les patients pédiatriques qui ont consulté à la clinique des angiomes entre 1998 et 2009. Ils ont obtenu des renseignements sur la démographie, l'aiguillage, le diagnostic et le traitement dans la base de données de la clinique.

RÉSULTATS : Des 932 patients, 621 ayant des hémangiomes et 311, des malformations vasculaires, faisaient partie de la base de données. Les hémangiomes s'observaient surtout chez les filles $(68,5 \%)$, sur la tête et dans le cou (54\%), et la plupart des patients $(72,6 \%)$ n'avaient qu'une lésion. Chez les patients présentant des hémangiomes, $14,7 \%$ ont subi une exploration d'imagerie diagnostique et $23,7 \%$ ont subi un traitement, y compris des médicaments, une opération, le laser à colorant pulsé ou des pansements. La distribution selon le sexe chez les 311 patients ayant des malformations vasculaires était presque égale. On observait des malformations veineuses chez 38,9\% des patients, des malformations capillaires isolées chez $31,5 \%$ des patients, des malformations lymphatiques chez $11,6 \%$ d'entre eux, des malformations mixtes à bas débit chez $14,8 \%$ des patients et des malformations artérioveineuses, chez 2,9\% d'entre eux. Dans l'ensemble, $37,9 \%$ des patients ont subi une exploration d'imagerie diagnostique et $42,4 \%$ ont été traités par laser à colorant pulsé, excision chirurgicale, sclérothérapie ou un autre traitement.

CONCLUSIONS : Des hémangiomes et des malformations vasculaires peuvent se manifester à n'importe quel foyer anatomique. On observe une vaste variation des présentations cliniques, qui exige des compétences à l'égard de diverses approches diagnostiques et modalités thérapeutiques. Les anomalies vasculaires sont mieux prises en charge en milieu multidisciplinaire.

other ancillary staff. Other available consultants include dermatologists, general surgeons, otolaryngologists and orthopedic surgeons. A plastic surgeon and a pediatrician evaluate all new patients referred to the clinic.

The epidemiology of patients seen in the clinic has not been previously characterized. The purpose of the present review was to gain a better understanding of the spectrum of the vascular anomalies encountered in the clinic and to identify trends in the management of these patients. It is hoped that this information will help others in allocating resources for this type of clinic.

\section{METHODS}

The present study was a retrospective data analysis of all pediatric patients presenting to the VBM Clinic at the $\mathrm{ACH}$ between 1998 and 2009. Patients were identified using an Oracle database (Oracle, USA) specifically constructed for the clinic in 2008. The

Section of Plastic Surgery, Section of Pediatric Surgery, Department of Surgery, University of Calgary, Calgary, Alberta

Correspondence: Dr Frankie OG Fraulin, Section of Pediatric Surgery, Alberta Children's Hospital, 2888 Shaganappi Trail Northwest,

Calgary, Alberta T3B 6A8. Telephone 403 955-2840, fax 403 955-7634, frankie.fraulin@albertahealthservices.ca 


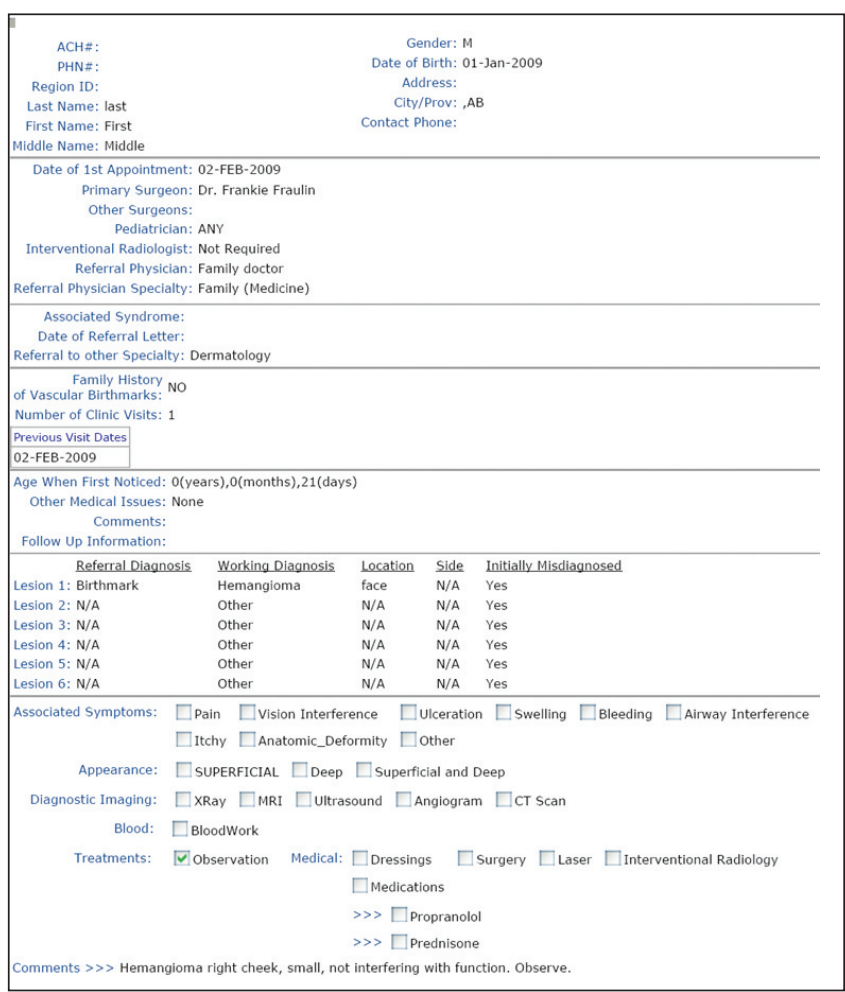

Figure 1) Example of a patient summary page in the database

development of this database has been previously described (3). Figure 1 is an example of a fictional patient's summary page in the database. Data collected included demographic and referring information such as age at referral, type of referring physician and referring diagnosis. Diagnostic and treatment information was also recorded and includes working diagnosis, significant symptoms and signs, investigations performed and treatments administered. Data were analyzed in an aggregate fashion and reported as proportions. No identifying information for individual patients was included. The present review was granted ethics approval by the Conjoint Health Research Ethics Board of the Faculties of Medicine, Nursing and Kinesiology, University of Calgary and the affiliated teaching institutions.

\section{RESULTS}

There were 1029 new patients seen in the VBM Clinic between 1998 and 2009. Of these patients, 621 (60.3\%) had hemangiomas, $311(30.2 \%)$ had vascular malformations and 97 (9.4\%) had a working diagnosis other than a vascular anomaly. The latter were excluded, leaving 932 patients with vascular anomalies. The catchment area for referral extended throughout Alberta and the surrounding provinces and was approximately two million people. The majority of these patients were referred from Calgary and southern Alberta ( $\mathrm{n}=788,84.5 \%$ ), with the remainder from central Alberta $(n=65,7 \%)$, Edmonton and northern Alberta $(n=15,1.6 \%)$, Saskatchewan $(n=30,3.2 \%)$, British Columbia $(n=30,3.2 \%)$, Manitoba $(n=2,0.2 \%)$ and other places $(n=2$, $0.2 \%$ ). The number of new patients seen is increasing each year. For example, there were 155 new patients in 2007, 160 new patients in 2008, 230 new patients in 2009 and 260 new patients in 2010. The total number of patient visits each year is also increasing; for example, there were 895 patient visits in 2009 and 1017 patient visits in 2010 .

\section{Hemangiomas}

Among the 621 patients with hemangiomas, 425 (68.5\%) were girls and $196(31.5 \%)$ were boys, representing a ratio of 2.2:1. Table 1 summarizes the characteristics of the patients with hemangiomas with regard to the number of hemangiomas per patient, location of the
TABLE 1

Hemangiomas

\begin{tabular}{|c|c|}
\hline Hemangiomas per patient, $n$ & $\%$ of total patients $(n=621)$ \\
\hline 1 & 72.6 \\
\hline 2 & 16.4 \\
\hline 3 & 6.0 \\
\hline 4 & 3.4 \\
\hline$\geq 5$ & 1.6 \\
\hline Anatomical location & $\%$ of total hemangiomas $(n=885)$ \\
\hline Head and neck & 54.0 \\
\hline Trunk & 21.7 \\
\hline Extremity & 21.0 \\
\hline Perineal & 2.4 \\
\hline Visceral & 0.9 \\
\hline Diagnostic imaging & $\%$ of total patients $(n=621)$ \\
\hline Ultrasound & 8.7 \\
\hline Magnetic resonance imaging & 5.6 \\
\hline Computed tomography & 1.5 \\
\hline X-ray & 0.3 \\
\hline Angiogram & 0.2 \\
\hline Treatment (147/621 patients) & Patients, $\mathrm{n}$ \\
\hline Phase & Proliferative (involution) \\
\hline Medications & $97(0)$ \\
\hline Wound care & $17(0)$ \\
\hline Surgery & $23(50)$ \\
\hline Laser & $4(12)$ \\
\hline
\end{tabular}

hemangiomas, diagnostic imaging modalities and treatment options. The 621 patients had a total of 885 lesions. Most patients $(n=451$, $72.6 \%$ ) had only one lesion. Lesions varied according to anatomical location, with the head and neck region being the most common (478 of 885 lesions [54\%]). Some form of diagnostic imaging investigation was performed in 91 of $621(14.7 \%)$ patients. Some patients had more than one modality of investigation. The most common form was ultrasound followed by magnetic resonance imaging (MRI). These 91 patients had a total of 151 lesions. Anatomically, these lesions were distributed in a pattern similar to all patients with hemangiomas, with the head and neck region the most common, with 84 of 151 (55.6\%) lesions. Patients with visceral hemangiomas were diagnosed using either MRI or ultrasound. PHACES syndrome was diagnosed in two patients based on clinical presentation and MRI.

Of the 621 patients with hemangiomas, 147 (23.7\%) required treatment. The main indications for treatment included anatomical deformity $(n=81)$, ulceration $(n=40)$, vision disturbance $(n=22)$ and airway obstruction $(n=4)$. Table 2 summarizes the percentage of hemangiomas treated in the proliferative and involution phases according to different anatomical locations: 155 of 885 (17.5\%) lesions treated in the proliferative phase and 81 of 885 (9.2\%) lesions treated in the involution phase. Approximately one-quarter (106 of 478 [22.2\%]) of all head and neck hemangiomas received treatment in the proliferative phase. Children with trunk and extremity lesions were least likely to require treatment. The sites with the lowest frequency of hemangiomas (perineal and visceral regions) had the highest percentage receiving treatment in the proliferative phase. Table 2 also specifically highlights the head and neck hemangiomas (478 lesions). The most common head and neck locations requiring treatment were periorbital, intraoral, ear, lip and cheek/chin.

The types of treatment received are summarized in Table 1. Of 621 patients, 147 received treatment in the proliferative phase, involution phase or both phases. In the proliferative phase, 111 patients underwent treatment, with some undergoing more than one modality of treatment. Medications were the most common treatment, specifically prednisone in 62 patients, a beta-blocker in 14 patients, and both 
TABLE 2

Treatment of hemangiomas according to anatomical location

\begin{tabular}{|c|c|c|c|c|c|c|c|c|c|}
\hline & \multicolumn{5}{|c|}{ Location } & & \multirow[b]{7}{*}{ Nose } & \multirow[b]{7}{*}{ Forehead } & \multirow[b]{7}{*}{ Scalp } \\
\hline & Head and neck & Trunk & Extremity & Perineal & Visceral & & & & \\
\hline Hemangiomas, n & 478 & 192 & 186 & 21 & 8 & & & & \\
\hline Treatment phase & \multicolumn{5}{|c|}{$\%$ treated in each phase } & & & & \\
\hline Proliferative & 22.2 & 8.9 & 11.3 & 38.1 & 60 & & & & \\
\hline Involution & 11.5 & 7.8 & 5.4 & 4.8 & 0 & & & & \\
\hline Head and neck & Periorbital & Intraoral & Ear & Lip & Cheek/chin & Neck & & & \\
\hline Hemangiomas, n & 65 & 13 & 25 & 61 & 80 & 46 & 41 & 34 & 113 \\
\hline Treatment phase & \multicolumn{9}{|c|}{$\%$ treated in each phase } \\
\hline Proliferative & 52.3 & 38.5 & 32 & 30 & 22.5 & 21.7 & 17.1 & 11.8 & 5.3 \\
\hline Involution & 9.2 & 0 & 12 & 16.4 & 18.8 & 8.7 & 19.5 & 14.7 & 3.5 \\
\hline
\end{tabular}

TABLE 3

Vascular malformations

\begin{tabular}{|c|c|c|c|c|c|}
\hline & \multicolumn{5}{|c|}{ Type of vascular malformation } \\
\hline & Venous & Capillary & Lymphatic & Mixed low flow & AVM \\
\hline Patients $(\mathrm{n}=311), \mathrm{n}(\%)$ & $121(38.9)$ & $98(31.5)$ & $36(11.6)$ & $43(14.8)$ & $9(2.9)$ \\
\hline$\%$ patients investigated & 38.8 & 18.4 & 66.7 & 46 & 100 \\
\hline \multirow[t]{3}{*}{$\%$ patients treated } & 30.1 & 41.8 & 63.9 & 51.2 & 100 \\
\hline & \multicolumn{5}{|c|}{ Investigations } \\
\hline & MRI & Ultrasound & Computed tomography & X-ray & Angiogram \\
\hline \multirow[t]{3}{*}{ Patients $(n=311), n(\%)$} & $99(31.8)$ & $52(16.7)$ & $5(1.6)$ & $5(1.6)$ & $4(1.3)$ \\
\hline & \multicolumn{4}{|c|}{ Treatment } & \\
\hline & Laser & Surgery & Sclerotherapy & Medical & \\
\hline Patients $(n=311), n(\%)$ & $50(16.1)$ & $47(15.1)$ & $32(10.3)$ & $31(10)$ & \\
\hline
\end{tabular}

AVM Arteriovenous malformation; MRI Magnetic resonance imaging

prednisone and a beta-blocker in 21 patients. Surgical debulking was the second most common treatment, performed on 23 patients, the majority of whom had periorbital lesions. Of these 111 patients, 22 also underwent treatment in the involution phase - either surgical excision or pulsed-dye laser treatment. A total of 58 patients, including these latter 22 patients, underwent treatment during the involution phase: 46 patients had surgery, eight patients had pulsed-dye laser treatment, and four patients had both surgery and pulsed-dye laser treatment.

\section{Vascular malformations}

Among the 311 patients with vascular malformations, an equal sex distribution was noted: 154 (49.5\%) girls and 157 (50.5\%) boys. Table 3 summarizes the frequency of the types of vascular malformations. Venous malformations were the most common followed by capillary malformations and then mixed low-flow malformations (combinations of capillary \pm venous \pm lymphatic). Mixed high-flow (arteriovenous malformation [AVM]) were the least common. Lowflow (isolated venous, capillary or lymphatic) malformations were most commonly found in the head and neck followed by the extremities. Mixed low-flow and AVMs, on the other hand, were more commonly found on the extremities followed by the head and neck. Mixed low-flow lesions were the most common category to be associated with a syndrome: 25 of 43 (58\%) of patients had Klippel-Trenaunay syndrome and one patient had Beckwith-Wiedmann syndrome. Three patients had Sturge-Weber syndrome.

Approximately one-third (118 of 311 [37.9\%]) of patients underwent a diagnostic imaging investigation (Table 3). Some patients had more than one modality of investigation. MRI was the most common modality, followed by ultrasound. Indications for investigation included diagnostic (diagnosis not clear clinically), evaluation of possible associated underlying abnormality (ie, capillary malformation over lower lumbar spine to evaluate for occult spine problem) or to determine the extent of the malformation in preparation for possible treatment.
Some form of treatment was performed in 132 of 311 (42.4\%) of patients (Table 3). Some patients had more than one modality of treatment. The most common overall treatment was laser treatment, most commonly using a pulsed-dye laser (Candela V-Beam, Syneron Medical Ltd, Canada) for capillary malformations, mainly of the head and neck. These patients had no symptoms and the treatment was mainly for appearance. Surgery was the second overall most common treatment followed by sclerotherapy. Medical treatment included adjuvant modalities such as compression stockings, intravenous antibiotics for cellulitis and anticoagulant therapy. Treatment for venous, lymphatic or mixed low-flow malformations was primarily indicated for symptoms of pain, swelling or bleeding. Patients with isolated lymphatic malformations were most commonly symptomatic (26 of 36 [72\%]), followed by patients with mixed low-flow malformations (26 of 43 [60.4\%]) and then isolated venous malformations (42 of 121 [34.7\%]). Table 3 reports the overall percentage of patients requiring investigation and treatment according to their diagnosis. The most common lesions, venous and capillary, were the least commonly treated. Patients with lymphatic malformations were more likely to undergo investigation and treatment. All nine patients with an AVM received investigation and treatment. These patients were symptomatic (Schobinger classification 2 or 3 ) and received treatment - either local wound control or combined surgery and embolization for definitive management.

\section{DISCUSSION}

The VBM Clinic at the ACH has evolved into a large, multidisciplinary tertiary clinic serving children in southern Alberta and adjacent portions of British Columbia and Saskatchewan. The clinic database was established to document activity in the clinic. The present study reviewed the epidemiological profile of these clinic patients. Our findings agree with other recent studies on vascular anomalies $(4,5)$. We found that hemangiomas occur more frequently than vascular malformations, accounting for $60.3 \%$ of patients seen in our clinic. Hemangiomas were more common in girls than in boys by a ratio of 
2.2:1, usually present as single lesions, and most commonly presented in the head and neck region (54\%). Despite being more common than vascular malformations, fewer hemangiomas required investigation (14.7\%), likely because most were superficial and the diagnosis was easily made on clinical grounds. The indications for investigation included: determining the extent of the hemangiomas, confirming the diagnosis, and identification of related intracranial or intraspinal abnormalities in certain patients with extensive facial lesions (ie, suspicion of PHACES) or midline lesions.

Most patients with hemangiomas $(76.3 \%)$ did not require treatment, but were monitored through the proliferative and involutional phases. This has been called "active nonintervention" in a recent review by Maguiness and Frieden (6). The other 23.7\% of patients received some form of treatment, which included medications, surgery, pulsed-dye laser or dressings. Medications were the most common treatment in the proliferative phase. Before 2009, prednisone was the firstline treatment. Following the report of the benefit of propranolol in several patients in July 2008 (7), we cautiously began using this betablocker in combination with prednisone. By the end of 2009, propranolol had become our first-line treatment because of the infrequent side effects. We are closely following the progress of all patients treated with beta-blockers to clarify optimal dosing and duration of treatment for these patients. We agree with others that current indications for treating hemangiomas include prevention or improvement of functional impairment or pain, prevention or improvement of scarring and/or disfigurement, and avoidance of life-threatening complications (6). The number of patients treated in the involution phase were not completely accurate because, at the time of the present report, many of the patients were not that far along in the involution phase. It is not yet clear whether they will require treatment for any remaining hemangiomas.

Vascular malformations were not as common as hemangiomas. They are considered errors in fetal development and tend to grow commensurately with the child and do not involute $(8,9)$. We found an equal sex distribution in all subtypes of vascular malformations, similar to others' observations $(8,9)$. In our clinic, venous malformations were most commonly followed by capillary malformations. Venous, capillary and lymphatic malformations presented most commonly in the head and neck regions, whereas mixed low-flow and high-flow malformations presented more commonly in the extremities. We found that patients with vascular malformations were more likely to undergo diagnostic imaging investigation than hemangiomas (37.9\% versus $14.7 \%)$. Also, a greater percentage of patients with vascular malformations received some form of treatment (42.4\% versus $23.7 \%$ ). In particular, approximately one-third of patients with venous malformations were symptomatic $(34.7 \%)$, and underwent diagnostic imaging investigation (38.8\%) and received treatment $(30.1 \%)$. Although most venous malformations were in the head and neck, the extremity venous malformations were more commonly treated. Capillary malformations can cause a significant cosmetic deformity, especially if they occur on the head and neck. Approximately one-fifth $(18.4 \%)$ of patients with isolated capillary malformations underwent investigation for associated anomalies. Currently, the pulsed-dye laser (Candela V-Beam) produces the best results in lightening capillary malformations. In the low-flow category, patients with lymphatic malformations had the highest percentage undergoing investigation $(66.7 \%)$ and receiving some form of treatment (63.9\%). The group of patients with mixed low-flow lesions was more likely to be symptomatic and to undergo investigation $(46.5 \%)$ and receive treatment $(51.2 \%)$ than those with isolated vascular malformations. Patients with AVMs were all symptomatic and all underwent investigation and treatment.

The present review of the experience in the VBM Clinic at the $\mathrm{ACH}$ highlights several issues pertaining to the management of vascular anomalies. First, they can occur in a wide variety of anatomical sites. Second, there is a large variation in clinical presentation necessitating expertise in clinical assessment and a variety of diagnostic approaches. Third, there are a variety of available treatment modalities that can cross several medical specialties. These findings confirm our and others' recommendation that vascular anomalies should be managed in a multidisciplinary setting that brings together expertise from different pediatric specialties including general pediatrics, plastic surgery, interventional radiology, general surgery, otolaryngology and orthopedics (9).

ACKNOWLEDGEMENTS: This project was supported by a grant from the Calgary Surgical Research Development Fund. The authors thank their database developer, Huijun Yu, and the Department of Surgery for their support of this project.

CONFLICTS OF INTEREST: The authors have no commercial association or other arrangements (financial compensation received, patient-licensing arrangements, potential to profit, consultancy, stock ownership, etc) that pose a conflict of interest in connection with this article.

\section{REFERENCES}

1. Mulliken JB, Glowacki J. Hemangiomas and vascular malformations in infants and children: A classification based on endothelial characteristics. Plast Reconstr Surg 1982;6:412-22.

2. Sibbald B. Calgary home to country's first comprehensive vascular birthmark clinic. CMAJ 1999;160:898.

3. Sharma VK, Fraulin FOG, Harrop AR, McPhalen DF.

The opportunities and obstacles in developing a vascular birthmark database for clinical and research use. Can J Plast Surg 2011;19:1-3.

4. Christison-Lagay ER, Fishman SJ. Vascular anomalies. Surg Clin N Am 2006;86:393-425.

5. Greene AK. Management of hemangiomas and other vascular tumors. Clin Plast Surg 2011;38:45-63.

6. Maguiness SM, Frieden IJ. Current management of infantile hemangiomas. Semin Cutan Med Surg 2010;29:106-14.

7. Leaute-Labreze C, Dumas de la Roque E, Hubiche T, Boralevi F Thambo JB, Taieb A. Propranolol for severe hemangiomas of infancy. N Engl J Med 2008;358:2649-51.

8. Arneja JS, Gosain AK. Vascular malformations. Plast Reconstr Surg 2008;121:195:e-206e.

9. Greene AK. Vascular anomalies: Current overview of the field. Clin Plast Surg 2011;38:1-5. 